OPEN ACCESS

Edited by:

Lothar Wondraczek,

University of Jena, Germany

Reviewed by:

Stefan Karlsson,

SP Technical Research Institute of

Sweden, Sweden

Mouritz Nolsøe Svenson,

Aalborg University, Denmark

*Correspondence:

Huidan Zeng

hdzeng@ecust.edu.cn

Specialty section:

This article was submitted to

Glass Science,

a section of the journal

Frontiers in Materials

Received: 24 September 2016 Accepted: 09 November 2016

Published: 21 November 2016

Citation:

Zeng $H$, Wang $L$, Ye $F$, Yang $B$, Chen J, Chen $G$ and Sun L (2016) Mechanical-Structural Investigation

of Chemical Strengthening

Aluminosilicate Glass through Introducing Phosphorus Pentoxide.

Front. Mater. 3:53.

doi: 10.3389/fmats.2016.00053

\section{Mechanical-Structural Investigation of Chemical Strengthening Aluminosilicate Glass through Introducing Phosphorus Pentoxide}

\author{
Huidan Zeng ${ }^{1 *}$, Ling Wang ${ }^{1}$, Feng Ye ${ }^{1}$, Bin Yang ${ }^{1}$, Jianding Chen ${ }^{1}$, Guorong Chen ${ }^{1}$ and \\ Luyi Sun ${ }^{2}$
}

${ }^{1}$ Key Laboratory for Ultrafine Materials of Ministry of Education, School of Materials Science and Engineering, East China University of Science and Technology, Shanghai, China, ${ }^{2}$ Polymer Program, Department of Chemical and Biomolecular Engineering, Institute of Materials Science, University of Connecticut, Storrs, CT, USA

Chemical strengthening of aluminosilicate glasses through $\mathrm{K}^{+}-\mathrm{Na}^{+}$ion exchange has attracted tremendous attentions because of the accelerating demand for high strength and damage resistance glasses. However, a paramount challenge still exists to fabricate glasses with a higher strength and greater depth of ion-exchange layer (DOL). Herein, aluminosilicate glasses with different contents of $\mathrm{P}_{2} \mathrm{O}_{5}$ were prepared, and the influence of $\mathrm{P}_{2} \mathrm{O}_{5}$ on the increased compressive stress (CS) and DOL was investigated by micro-Raman technique. It was noticed that the hardness, CS, as well as the DOL substantially increased with an increasing concentration of $\mathrm{P}_{2} \mathrm{O}_{5}$ varied from 1 to $7 \mathrm{~mol} \%$. The obtained micro-Raman spectra confirmed the formation of relatively depolymerized silicate anions that accelerated the ion exchange. Phosphorus-containing aluminosilicate glasses with a lower polymerization degree exhibited a higher strength and deeper DOL, which suggests that the phosphorus-containing aluminosilicate glasses have promising applications in flat panel displays, windshields, and wafer sealing substrates.

Keywords: chemical strengthening, ion-exchange layer, compressive stress, $\mathrm{P}_{2} \mathrm{O}_{5}$, micro-Raman

\section{INTRODUCTION}

The development of ultrathin, high strength, and damage resistance glasses for flat panel displays, windshields, and wafer sealing substrates is an ongoing challenge (Wondraczek et al., 2011; Käfer et al., 2013; Mauro et al., 2016). Traditionally, the practical strength of glasses is two orders of magnitude lower than the theoretical value due to the flaws and defects on the glass surface (Wiederhorn et al., 2013). It is therefore of the outmost importance to eliminate the defects to improve the strength. Various methods of glass strengthening have been developed extensively over the last few decades, such as thermal tempering (Solinov, 2015), chemical strengthening (Olcott, 1963; Karlsson et al., 2010; Varshneya, 2010a,b), and surface crystallization (Donald, 1989). It is noteworthy that chemical strengthening, which is achieved essentially by immersing an alkali-containing glass in a molten salt bath, generates high compressive stress (CS) in thin or irregularly shaped glass objects without measureable optical distortion, making it the leading candidate for strengthening of glasses (Kistler, 1962; Olcott, 1963; Karlsson et al., 2010; Varshneya, 2010a,b). The chemical strengthening properties of glasses are typically characterized by CS and depth of ion-exchange layer (DOL). 
Moreover, these properties depend much on glass composition and topological restriction (Smedskjaer et al., 2010; Vargheese et al., 2014; Calahoo et al., 2016).

Chemically strengthened aluminosilicate glasses through $\mathrm{K}^{+}-\mathrm{Na}^{+}$ion exchange are currently receiving significant interest due to their excellent mechanical properties (Chang et al., 2014). Previous researches indicated that the DOL of high-alkali aluminosilicate glasses can reach $30-75 \mu \mathrm{m}$ at $430-490^{\circ} \mathrm{C}$ for 3-8 $\mathrm{h}$, and the hardness can be enhanced (Wu et al., 2011; Jiang et al., 2013). Because of the increasing demand for high strength and damage resistance glasses, new methods to enhance CS, DOL, and hardness have become a focus of research. Up to now, many investigations on the strengthening process, molten salt, and glass composition have been carried out (Nordberg et al., 1964; Anna and Mauro, 2013; Svenson et al., 2014; Sglavo, 2015). However, the treatment of aluminosilicate glasses was limited in chemical strengthening due to the relatively small DOL. A large value of DOL is required to embed surface flaws and defects in the compressive stress layer. For the glasses designed with a fixed value of DOL, significant cost saving can be achieved by increasing the ion diffusion rate and thus shortening the ionexchange time. Previous researchers suggested that the addition of $\mathrm{P}_{2} \mathrm{O}_{5}$ can accelerate the process of ion exchange and increase the DOL (Burggraaf and Cornelissen, 1964; Zhang et al., 2012; Bookbinder et al., 2013; Chapman et al., 2014). However, it still remains a grand challenge to reveal the underlying mechanism of ion-exchanged aluminosilicate glasses through introducing $\mathrm{P}_{2} \mathrm{O}_{5}$.

In this study, the effect of $\mathrm{P}_{2} \mathrm{O}_{5}$ on the structure and mechanical properties of ion-exchanged aluminosilicate glasses was systematically investigated. The diffusion coefficient and activation energy $E a$ of ion-exchanged $x \mathrm{P}_{2} \mathrm{O}_{5}-(100-x)\left(0.25 \mathrm{Na}_{2} \mathrm{O}-\right.$ $\left.0.08 \mathrm{Al}_{2} \mathrm{O}_{3}-0.67 \mathrm{SiO}_{2}\right)(x=5)$ glass treated at $400^{\circ} \mathrm{C}$ for different ion-exchange times and different ion-exchange temperatures for $6 \mathrm{~h}$ were calculated. Then, the hardness, CS, and DOL were measured with the addition of $\mathrm{P}_{2} \mathrm{O}_{5}$. Furthermore, the topological structure evolution of phosphorus-containing aluminosilicate glasses was observed by micro-Raman technique to comprehensively analyze the mechanism of ion-exchange strengthening.

\section{EXPERIMENTAL}

A series of $x \mathrm{P}_{2} \mathrm{O}_{5}-(100-x)\left(0.25 \mathrm{Na}_{2} \mathrm{O}-0.08 \mathrm{Al}_{2} \mathrm{O}_{3}-0.67 \mathrm{SiO}_{2}\right)$ $(x=1,3,5,6$, and $7 \mathrm{~mol} \%$, respectively) glass samples were prepared by conventional melt-quenching technique using $\mathrm{Na}_{2} \mathrm{CO}_{3}$, $\mathrm{SiO}_{2}$, and $\mathrm{Al}(\mathrm{OH})_{3}$ from Sinopharm Chemical Reagent Company and $\mathrm{AlPO}_{4}$ from Aladdin. The starting materials (ca. $20 \mathrm{~g}$ ) were thoroughly mixed in an agate mortar, and the homogeneous mixture was transferred into a corundum crucible and preheated at $800^{\circ} \mathrm{C}$ for $30 \mathrm{~min}$ before being fully melted at temperatures between 1550 and $1650^{\circ} \mathrm{C}$, depending on the composition. The liquid melt was kept at this temperature for an hour to ensure homogenization before it was cooled rapidly in a preheated brass mold to form bulk glasses and annealed at $560^{\circ} \mathrm{C}$ for $4 \mathrm{~h}$ to diminish internal stresses. Then, the glass samples were allowed to cool to room temperature. Such glasses were cut and polished into $2 \mathrm{~mm}$ for ion-exchange treatment. In the ion-exchange process, sample $5 \mathrm{P}_{2} \mathrm{O}_{5}-95\left(0.25 \mathrm{Na}_{2} \mathrm{O}-0.08 \mathrm{Al}_{2} \mathrm{O}_{3}-0.67 \mathrm{SiO}_{2}\right)$ was immersed into a molten $\mathrm{KNO}_{3}$ salt bath at different temperatures (390, $400,410,420$, and $\left.430^{\circ} \mathrm{C}\right)$ for different durations $(2,4,6,8$, and $10 \mathrm{~h}$ ). Other samples were treated in a molten $\mathrm{KNO}_{3}$ salt bath by submersion at $400^{\circ} \mathrm{C}$ for $6 \mathrm{~h}$. Then, the glass specimens were carefully cleaned with deionized water followed by ethanol and stored in a desiccator.

The Vickers hardness value of the polished glasses was determined with micro-indenter (HXD-1000TMC/LCD, Shanghai Taiming Optical Instrument Co. Ltd., Shanghai, China) at room temperature, where the indentation was performed on the surface of each sample at a load of $0.98 \mathrm{~N}$ for $10 \mathrm{~s}$. A minimum of 24 indents were measured on each sample. Error bars in the figures all represent the SD across the measured values of hardness. The measurement error for the hardness was less than $\pm 4 \%$. The DOL for each sample was measured on a field-emission scanning electron microscope (FESEM) equipped with an energy-dispersive spectrometer (EDS) in line scan mode (S-4800, Hitachi, Tokyo, Japan), where the acceleration voltage was $15.0 \mathrm{kV}$. Based on the potassium and sodium ion concentration profiles in the ion-exchanged glass surface, the DOL was determined when the potassium and sodium ion concentration profiles reached virtually 0 and a constant value, respectively. The CS was measured by using a surface stress meter (FSM-6000LE, Orihara, Tokyo, Japan). Birefringence can be used to directly probe the compressive stress found in the ion-exchange layer because of the compositional gradient. The measurement error for DOL and CS were less than $\pm 5 \%$. Micro-Raman spectra were recorded to investigate the topological structure of glass samples. A Raman spectrometer (INVIA, Renishaw, Gloucestershire, England) with an $\mathrm{Ar}^{+}$-ion laser $(514.5 \mathrm{~nm})$ as the irradiation source was employed. Baseline correction was performed using the Wire software program from Renishaw.

\section{RESULTS AND DISCUSSION}

The DOL and diffusion coefficients of ion-exchanged $x \mathrm{P}_{2} \mathrm{O}_{5}-$ $(100-x)\left(0.25 \mathrm{Na}_{2} \mathrm{O}-0.08 \mathrm{Al}_{2} \mathrm{O}_{3}-0.67 \mathrm{SiO}_{2}\right)(x=5)$ glass treated at $400^{\circ} \mathrm{C}$ for different ion-exchange times and different ion-exchange temperatures for $6 \mathrm{~h}$ are shown in Figures 1A,B, respectively. Obviously, the DOL is directly related to the ion-exchange time and temperature. With an increasing ion-exchange time and temperature, the DOL drastically increases. It is noteworthy that the DOL for such glasses is higher or comparable with some commercial glasses (Wang et al., 2008; Stavrou et al., 2014), which is desirable for chemically strengthened glasses. To understand the diffusion kinetics of $\mathrm{K}^{+}$ions in such glasses, the diffusion coefficient and activation energy must be determined. The diffusion coefficient as a function of the local concentration $D(C)$ can be calculated in accordance with the Boltzmann-Matano approach (Matano, 1933; Barton, 1975):

$$
D(C)=-\frac{1}{2 t} \frac{d x}{d C} \int_{0}^{C} x d C
$$

where $D(C)$ is the diffusion coefficient as a function of the local $\mathrm{K}^{+}$ion concentration, $x$ is the distance from the glass surface, 
$C$ is the $\mathrm{K}^{+}$ion concentration, and $t$ is the duration of the diffusion process.

The rate of alkali interdiffusivity depends on the free volume (atomic packing fraction) of the glass network structure (Svenson et al., 2016). And the activation energy has been found to scale with the free volume in the related studies on $\mathrm{K}^{+}-\mathrm{Na}^{+}$interdiffusivity (Potuzak and Smedskjaer, 2014; Smedskjaer et al., 2015). The activation energy $E a(\mathrm{~J} / \mathrm{mol})$ for ionic diffusion can be calculated using the Arrhenius equation (Frischat et al., 1975):

$$
D=D_{0} \exp \left(-\frac{E a}{R T}\right)
$$

where $D_{0}$ is a constant, $E a$ is the activation energy for the diffusion process, $R$ is the ideal gas constant, and $T$ is the absolute temperature. Plotting $\ln D$ versus $T^{-1}$ gives the slope $k=-E a / R$. The activation energy is assumed to be independent of the temperature.

As shown in Figure 1, the resultant diffusion coefficient increases with an increasing temperature. However, the diffusion

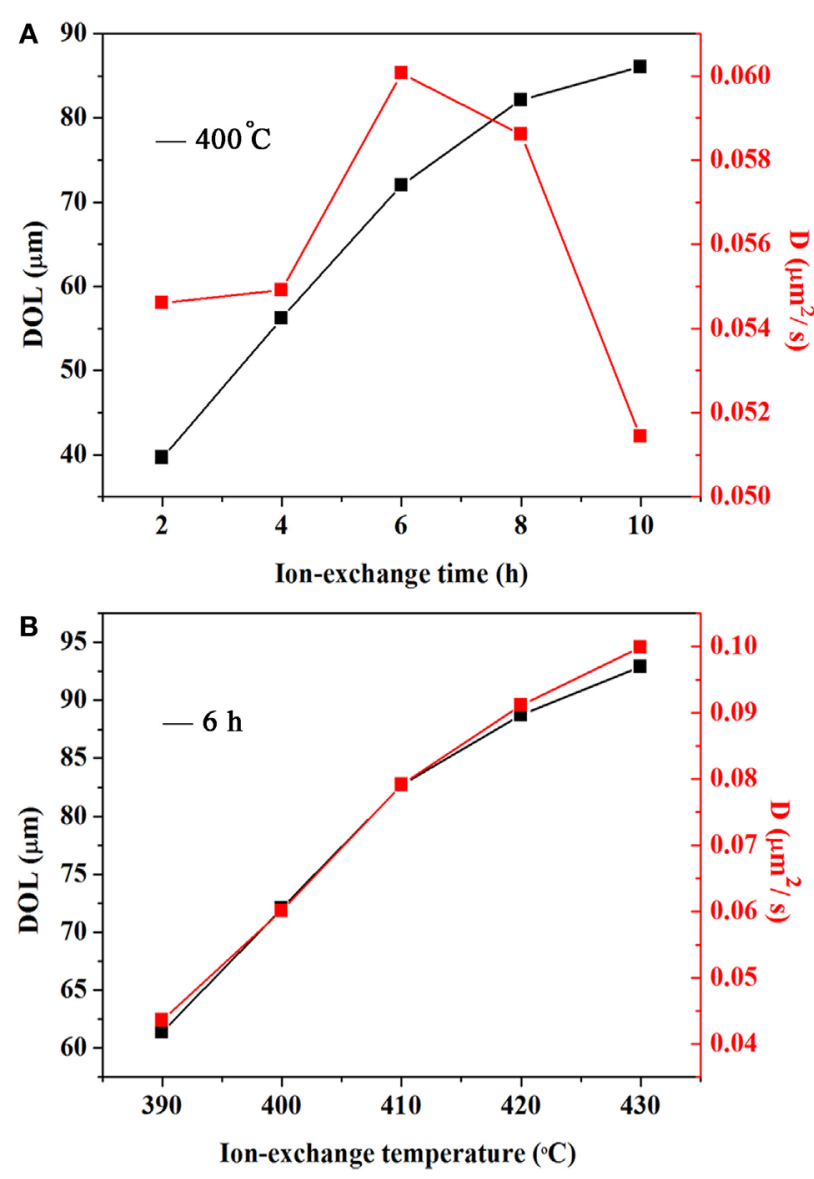

FIGURE 1 | DOL and diffusion coefficient of ion-exchanged $x \mathrm{P}_{2} \mathrm{O}_{5}$ $(100-x)\left(0.25 \mathrm{Na}_{2} \mathrm{O}-0.08 \mathrm{Al}_{2} \mathrm{O}_{3}-\mathbf{0 . 6 7 5 i O}\right)(x=5)$ glass. (A) DOL and diffusion coefficient of the glass treated at $400^{\circ} \mathrm{C}$ for different ion-exchange durations; (B) DOL and diffusion coefficient of the glass treated at different ion-exchange temperatures for $6 \mathrm{~h}$. coefficient increases with the ion-exchange time until it reaches the maximum of $6 \mathrm{~h}$ and then decreases with a longer ionexchange time. This result may be due to the accumulation of $\mathrm{K}^{+}$ions in the glass surface that decreases the ion diffusion. The $E a$ is obtained by fitting the diffusion coefficient data using the Arrhenius equation. The activation energy $E a$ for ionic diffusion is shown in Figure 2. The red line is the linear fitting result. The calculated $E a$ value is ca. $80.8 \mathrm{~kJ} / \mathrm{mol}$, which is smaller than the values (sodium aluminosilicate glass, $95.4 \mathrm{~kJ} / \mathrm{mol}$; soda-limesilica float glass, $152 \mathrm{~kJ} / \mathrm{mol}$ ) reported in the literature (Shen et al., 2003). The reduced activation energy favors the diffusion of $\mathrm{K}^{+}-\mathrm{Na}^{+}$ions that promote the ion exchange in such phosphoruscontaining aluminosilicate glasses.

Moreover, as can be observed from Figure 3, ion exchange of the raw glasses leads to a pronounced increase in hardness. As the ion-exchange time and temperature is increased, the hardness increases until $400^{\circ} \mathrm{C}$ for $6 \mathrm{~h}$ and then decreases. The maximum hardness in the studied glass is up to $5.9 \mathrm{GPa}$. The increment in hardness is mainly attributed to the formation of surface compression through ion exchange, and the hardness decreases afterward is because of the structural relaxation (Garfinkel and King, 1970; Donald, 1989).

Based on the above results, the relatively optimized ionexchange treatment in $x \mathrm{P}_{2} \mathrm{O}_{5}-(100-x)\left(0.25 \mathrm{Na}_{2} \mathrm{O}-0.08 \mathrm{Al}_{2} \mathrm{O}_{3}-\right.$ $\left.0.67 \mathrm{SiO}_{2}\right)(x=1,3,5,6$, and $7 \mathrm{~mol} \%$, respectively) glasses is performed at $400^{\circ} \mathrm{C}$ for $6 \mathrm{~h}$. The Vickers hardness values of $x \mathrm{P}_{2} \mathrm{O}_{5}-(100-x)\left(0.25 \mathrm{Na}_{2} \mathrm{O}-0.08 \mathrm{Al}_{2} \mathrm{O}_{3}-0.67 \mathrm{SiO}_{2}\right)(x=1,3,5$, 6 , and $7 \mathrm{~mol} \%$, respectively) glasses treated at $400^{\circ} \mathrm{C}$ for $6 \mathrm{~h}$ were plotted as a function of the concentration of $\mathrm{P}_{2} \mathrm{O}_{5}$ and are shown in Figure 4A. With an increasing concentration of $\mathrm{P}_{2} \mathrm{O}_{5}$, the hardness of the untreated glasses decreases from about 5.1 to $4.8 \mathrm{GPa}$. On the contrary, the hardness of the glass samples with ion exchange significantly increases from 5.5 to 6.1 $\mathrm{GPa}$ with an increasing concentration of $\mathrm{P}_{2} \mathrm{O}_{5}$, indicating

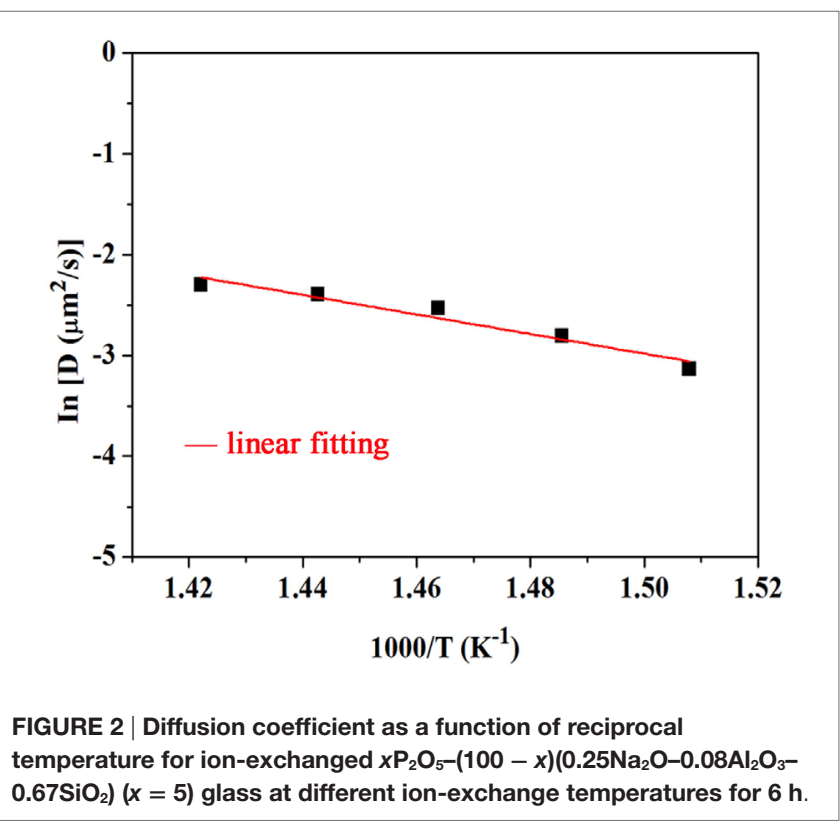



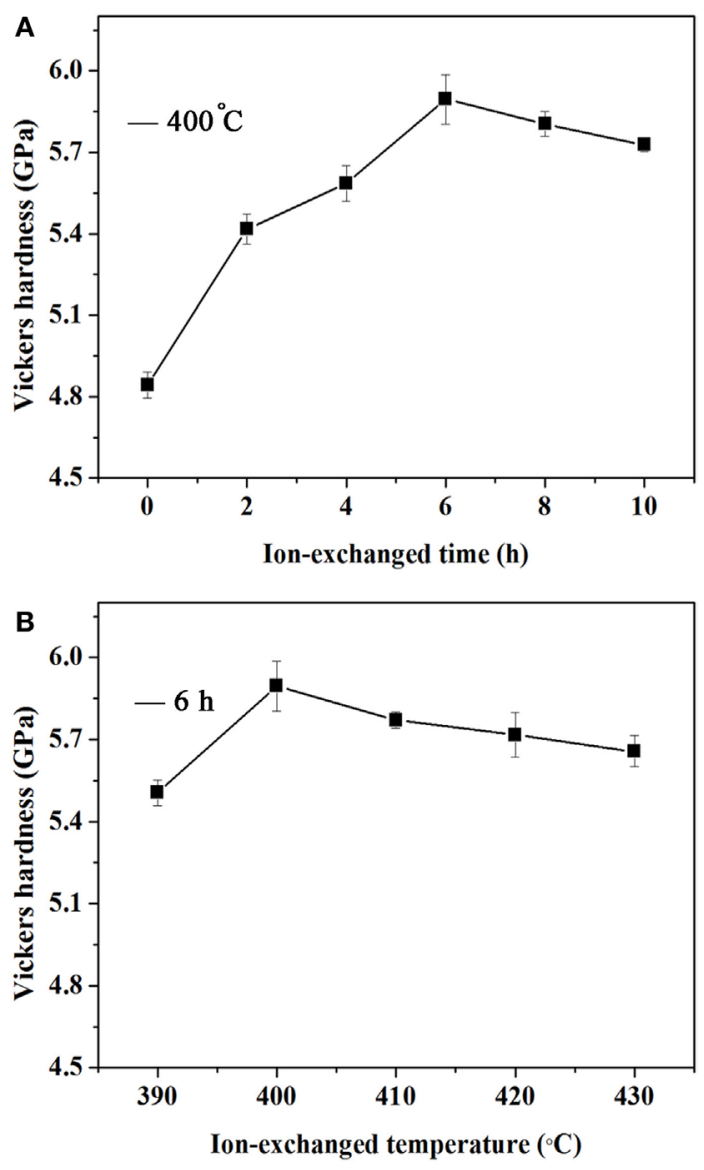

FIGURE 3 | Vickers hardness values of $x \mathrm{P}_{2} \mathrm{O}_{5}-(100-x)\left(0.25 \mathrm{Na}_{2} \mathrm{O}-\right.$ $\left.0.08 \mathrm{Al}_{2} \mathrm{O}_{3}-0.67 \mathrm{SiO}_{2}\right)(x=5)$. (A) Vickers hardness values of the glass treated at $400^{\circ} \mathrm{C}$ for different ion-exchange durations; (B) Vickers hardness values of the glass treated at different ion-exchange temperatures for $6 \mathrm{~h}$.

that the addition of $\mathrm{P}_{2} \mathrm{O}_{5}$ can enhance the strength through ion exchange. In addition, the result can be further confirmed by the images of the indentations in Figure 4B, which shows that the diagonal length of the indentations $(d)$ becomes smaller with an increasing concentration of $\mathrm{P}_{2} \mathrm{O}_{5}$. Because of the slight increase in hardness when $x>5 \mathrm{~mol} \%$, the change of indentation is not obvious.

Ion exchange between $\mathrm{K}^{+}$and $\mathrm{Na}^{+}$ions lead to the development of high surface compressive stress. Meanwhile, the strengthening treatment was carried out at a temperature below the annealing range, so that the stress introduced is not removed by relaxation. Figure 5 shows the linear increase of CS and DOL with an increase in $\mathrm{P}_{2} \mathrm{O}_{5}$ concentration. It is observed that the CS is monotonically improved when $\mathrm{P}_{2} \mathrm{O}_{5}$ concentration was increased, which is basically identical to the tendency of hardness. Additionally, the DOL increases with an increase in $\mathrm{P}_{2} \mathrm{O}_{5}$ concentration from 1 to $7 \mathrm{~mol} \%$. This is due to the change in atomic packing factor of the glasses with varying $\mathrm{P}_{2} \mathrm{O}_{5}$ that promotes the $\mathrm{K}^{+}-\mathrm{Na}^{+}$interdiffusivity. Therefore, it is interesting to note that the presence of $\mathrm{P}_{2} \mathrm{O}_{5}$ in aluminosilicate glasses enables the glass to be ion-exchanged

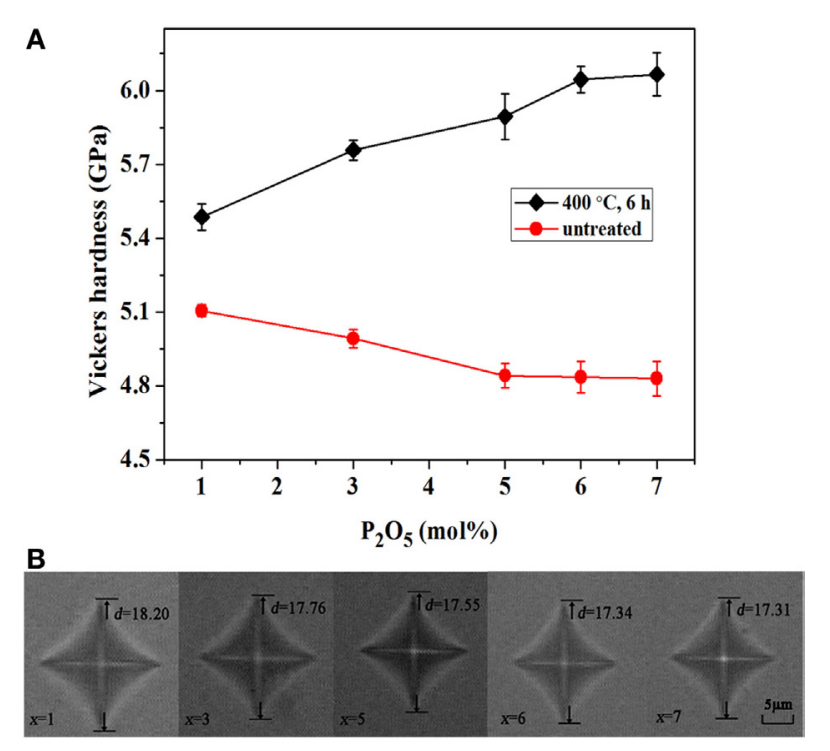

FIGURE 4 | Vickers hardness values of $x \mathrm{P}_{2} \mathrm{O}_{5}-(100-x)\left(0.25 \mathrm{Na}_{2} \mathrm{O}-\right.$ $\left.0.08 \mathrm{Al}_{2} \mathrm{O}_{3}-0.67 \mathrm{SiO}_{2}\right)(x=1,3,5,6$, and $7 \mathrm{~mol} \%$, respectively) glass series treated at $400^{\circ} \mathbf{C}$ for $6 \mathrm{~h}$. (A) Vickers hardness as a function of the concentration of $\mathrm{P}_{2} \mathrm{O}_{5}$ at room temperature before and after ion-exchange treatment; $(\mathbf{B})$ images of the indentations of ion-exchanged glasses after a load of $0.98 \mathrm{~N}$ for $10 \mathrm{~s}$.

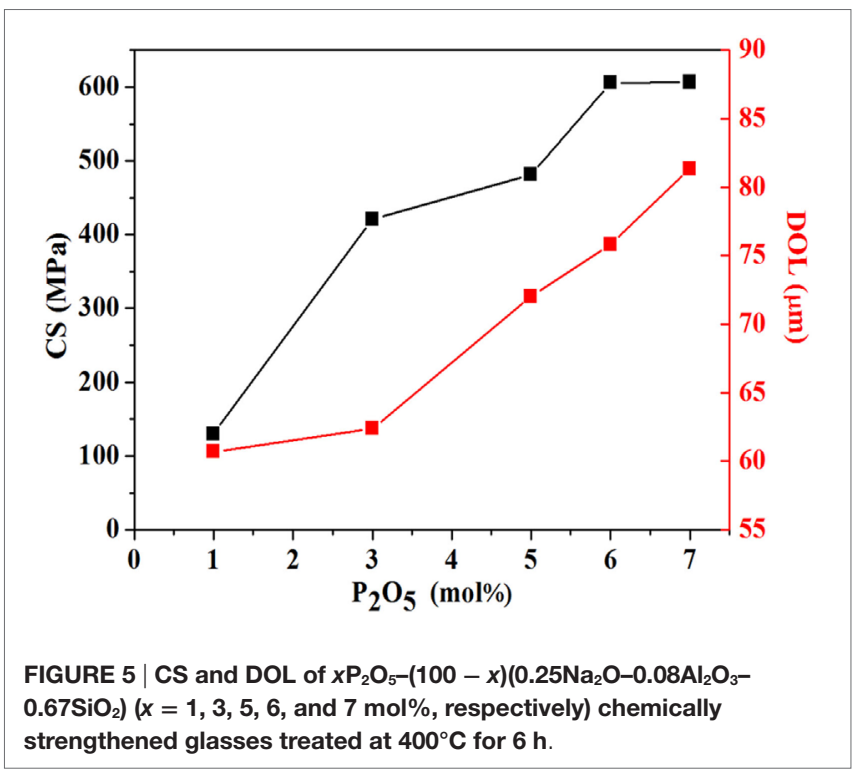

more efficiently and to a greater depth that effectively enhance the strength and damage resistance of the glass.

Micro-Raman spectroscopy can be used to determine the structural modifications occurring in the glasses. In Figure 6, spectra are shown as a function of an increasing $\mathrm{P}_{2} \mathrm{O}_{5}$ content from 1 to $7 \mathrm{~mol} \%$ in the range of $400-1500 \mathrm{~cm}^{-1}$. In the following discussion, $\mathrm{P}^{(n)}$ represents a $\left[\mathrm{PO}_{4}\right]$ tetrahedron with $n$ bridging oxygen, and the symbol Si ${ }^{(n)}$ represents a $\left[\mathrm{SiO}_{4}\right]$ tetrahedron with $n$ bridging oxygen. 


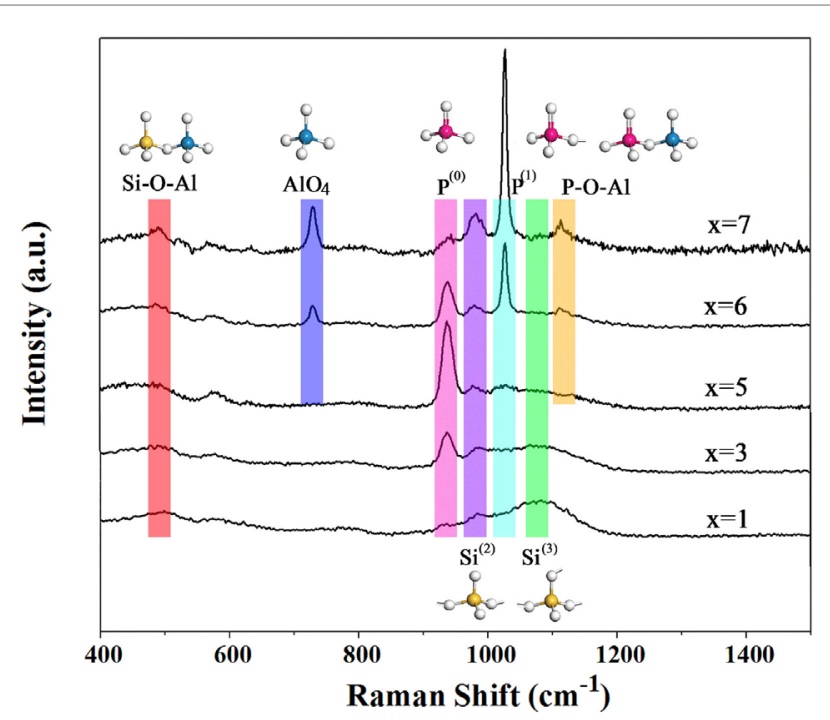

FIGURE 6 Micro-Raman spectra of aluminosilicate glasses with $x$ mol\% $\mathrm{P}_{2} \mathrm{O}_{5}$ concentration ( $x=1,3,5,6$, and $7 \mathrm{~mol} \%$, respectively).

The spectra of low $-\mathrm{P}_{2} \mathrm{O}_{5}$ glass show four major features centered near 500, 936, 980, and $1090 \mathrm{~cm}^{-1}$, respectively. With an increasing content of $\mathrm{P}_{2} \mathrm{O}_{5}$, several new peaks appeared in 730,1024 , and $1120 \mathrm{~cm}^{-1}$. The low-frequency region exhibits a maximum near $500 \mathrm{~cm}^{-1}$ with a shoulder or peak on both the lowand high-frequency side (near 500 and $600 \mathrm{~cm}^{-1}$, respectively) attributes to an oxygen breathing mode of the centers of four- and three-membered rings, respectively, which are contained in a tetrahedral structure (Lazzeri and Mauri, 2003). With an increasing content of $\mathrm{P}_{2} \mathrm{O}_{5}$, the shoulder or band frequencies near $500 \mathrm{~cm}^{-1}$ appear insensitive to $\mathrm{P}_{2} \mathrm{O}_{5}$ content. The band near $936 \mathrm{~cm}^{-1}$ is assigned to $\mathrm{P}-\mathrm{O}$ symmetric stretching of non-bridging oxygen ions in orthophosphate units $\left[\mathrm{PO}_{4}\right]^{-3}$ or $\mathrm{P}^{(0)}$. The high-frequency region $\left(>900 \mathrm{~cm}^{-1}\right)$ of the spectra of $\mathrm{P}_{2} \mathrm{O}_{5}$ glass varies significantly with $\mathrm{P}_{2} \mathrm{O}_{5}$ content. In the spectra of low- $\mathrm{P}_{2} \mathrm{O}_{5}$ glasses, the Raman spectra exhibit a characteristics strong band near $936 \mathrm{~cm}^{-1}$ assigned to $\mathrm{P}-\mathrm{O}$ stretching in orthophosphate complexes together with a weak band near $1024 \mathrm{~cm}^{-1}$ assigned to bending vibration in pyrophosphate units $\left[\mathrm{PO}_{3} \mathrm{O}_{1 / 2}\right]^{-2}$ or $\mathrm{P}^{(1)}$ (Mysen, 1996). With an increasing $\mathrm{P}_{2} \mathrm{O}_{5}$ content, the Raman spectrum intensity centered near $1024 \mathrm{~cm}^{-1}$ becomes remarkably more intense. The proportion of $\mathrm{P}^{(1)}$ initially increased relative to $\mathrm{P}^{(0)}$ and was joined by $\mathrm{AlPO}_{4}$ complexes which exhibit a characteristic $\mathrm{P}-\mathrm{O}$ stretch mode slightly above $1100 \mathrm{~cm}^{-1}$ (Jin et al., 1986). The decrease in $\mathrm{P}^{(0)} / \mathrm{P}^{(1)}$ with an increasing $\mathrm{P}_{2} \mathrm{O}_{5}$ content results in depolymerization of the silicate melts (Mysen, 1998).

The Raman bands observed from 650 to $750 \mathrm{~cm}^{-1}$ are attributed to the presence of $\mathrm{Al}_{2} \mathrm{O}_{3}$. Iwamoto et al. (1978) attributed the peak at $700-800 \mathrm{~cm}^{-1}$ to the contribution of $\mathrm{AlO}_{4}$ tetrahedral. And the intensity of $\mathrm{AlO}_{4}$ is related to $\mathrm{AlPO}_{4}$ in $1120 \mathrm{~cm}^{-1}$. With an increasing content of $\mathrm{P}_{2} \mathrm{O}_{5}$, the $\mathrm{Al}-\mathrm{O}-\mathrm{P}$ network increases.

The bands located at 980 and $1090 \mathrm{~cm}^{-1}$ contribute to the stretching vibration mode in $\mathrm{Si}^{(2)}$ and $\mathrm{Si}^{(3)}$, respectively (Aguiar et al., 2009). A further $\mathrm{P}_{2} \mathrm{O}_{5}$ increase results in a rapid

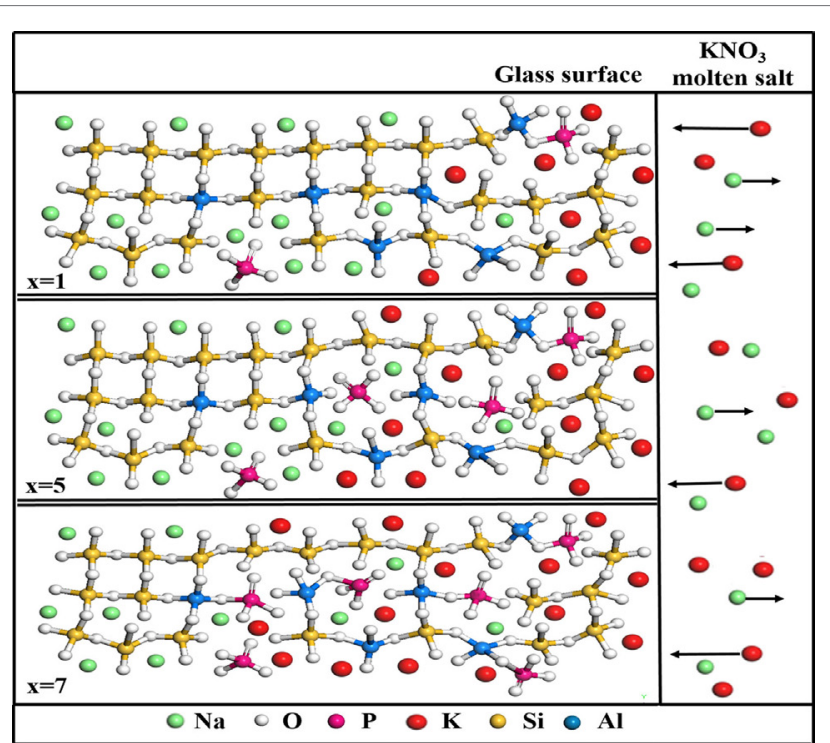

FIGURE 7 | Schematic plot of ion-exchange process in the glass surface at various concentrations of $\mathrm{P}_{2} \mathrm{O}_{5}(x=1,5$, and $7 \mathrm{~mol} \%)$ treated at $400^{\circ} \mathrm{C}$ for $6 \mathrm{~h}$.

disappearance of $\mathrm{Si}^{(3)}$ and an increase of $\mathrm{Si}^{(2)}$ with this region of the spectra gradually becoming dominated by a maximum near $1024 \mathrm{~cm}^{-1}$. So in these glasses, based on the structure change of $\mathrm{Si}^{(3)}$ and $\mathrm{Si}^{(2)}$, it is clear that both extra non-bridging oxygen ions and positive cations are needed in the transformation process from $\mathrm{Si}^{(3)}$ to $\mathrm{Si}^{(2)}$. And they could only be scavenged from the original phosphor network. As the phosphor network loses some of non-bridging oxygen ions and positive cations from $\mathrm{P}^{(0)}$ to $\mathrm{P}^{(1)}$, the peaks of $\mathrm{P}^{(0)}$ and $\mathrm{Si}^{(3)}$ gradually become less prominent with an increase of $\mathrm{P}_{2} \mathrm{O}_{5}$, and the opposite trend is true for the peaks of $\mathrm{P}^{(1)}$ and $\mathrm{Si}^{(2)}$, following a chemical reaction:

$$
\mathrm{P}^{(0)}+\mathrm{Si}^{(3)} \rightarrow \mathrm{P}^{(1)}+\mathrm{Si}^{(2)}
$$

The law for the structure development is consistent with the equilibrium of Le Chatelier's principle (Chatelier, 1888; Toplis and Schaller, 1998). As the phosphor network loses some nonbridging oxygen ions, the degree of polymerization of silicate network decreases, namely, the formation of relatively depolymerized silicate anions. Therefore, this topological evolution reveals that aluminosilicate glasses with $x$ mol\% $\mathrm{P}_{2} \mathrm{O}_{5}$ addition $(x=1,3,5,6$, and $7 \mathrm{~mol} \%)$ can accelerate the ion exchange and result in a greater depth of ion exchange.

Additionally, on the basis of the Raman spectroscopic results, we developed a schematic plot of ion exchange process in glass surface at various concentrations of $\mathrm{P}_{2} \mathrm{O}_{5}$, as shown in Figure 7. Along with an increasing concentration of $\mathrm{P}_{2} \mathrm{O}_{5}$, the network of glass surface is "opened" due to the decrease of polymerization degree of the glass, which is beneficial for the exchange of $\mathrm{Na}^{+}$ with $\mathrm{K}^{+}$in the glass surface by interdiffusion upon submersion in a liquid molten salt bath $\left(\mathrm{KNO}_{3}\right)$. This results in the formation of a compressive stress on surface and enhancement of DOL, strength, and damage resistance of the glass. 


\section{CONCLUSION}

Phosphorus-containing aluminosilicate glasses strengthened by ion exchange were developed, and their mechanical properties and DOL were characterized. The diffusion coefficients and activation energy were calculated by the Boltzmann-Matano approach and the Arrhenius equation. The higher diffusion coefficient and lower activation energy favor the diffusion of $\mathrm{K}^{+}-\mathrm{Na}^{+}$ that promotes the ion exchange in these phosphorus-containing aluminosilicate glasses. The increased hardness, DOL, and CS indicate the addition of $\mathrm{P}_{2} \mathrm{O}_{5}$ is an appealing approach to improve the strength of ion-exchanged glasses and to a greater depth of ion exchange layer. Furthermore, the obtained micro-Raman spectra show the evidence for the formation of relatively depolymerized silicate anions, indicating a decrease of polymerization degree that accelerates the ion exchange. The schematic of ion exchange at various concentrations of $\mathrm{P}_{2} \mathrm{O}_{5}$ is proposed, which suggests that the presence of $\mathrm{P}_{2} \mathrm{O}_{5}$ in chemically strengthened aluminosilicate glasses increases the DOL and strength. Because of their convenient manufacturing, such kind of phosphorus-containing aluminosilicate glasses may find promising applications in flat panel displays, windshields, and wafer sealing substrates.

\section{REFERENCES}

Aguiar, H., Serra, J., González, P., and León, B. (2009). Structural study of solgel silicate glasses by IR and Raman spectroscopies. J. Non Cryst. Solids 355, 475-480. doi:10.1016/j.jnoncrysol.2009.01.010

Anna, I. F., and Mauro, J. C. (2013). Mutual diffusivity, network dilation, and salt bath poisoning effects in ion-exchanged glass. J. Non Cryst. Solids 363, 199-204. doi:10.1016/j.jnoncrysol.2012.12.037

Barton, G. (1975). The mathematics of diffusion. Physics Bullet. 26, 500. doi:10.1088/0031-9112/26/11/044

Bookbinder, D. C., Gross, T. M., and Potuzak, M. (2013). Ion Exchangeable Glass with Deep Compressive Layer and High Damage Threshold. E.P. Patent $2646378 \mathrm{~A} 1$.

Burggraaf, A. J., and Cornelissen, J. (1964). The strengthening of glass by ion exchange: part 1. Phys. Chem. Glasses 5, 123-129.

Calahoo, C., Zwanziger, J. W., and Butler, I. S. (2016). Mechanical-structural investigation of ion-exchanged lithium silicate glass using micro-Raman spectroscopy. J. Phys. Chem. C 120, 7213-7232. doi:10.1021/acs.jpcc.6b01720

Chang, K. C., Tung, L. T., and Liu, Y. C. (2014). The mechanical properties of aluminosilicate glass with chemical strengthening. SID Symp. Digest Technol. Pap. 45, 1226-1229. doi:10.1002/j.2168-0159.2014.tb00320.x

Chapman, C. L., Dejneka, M. J., Gomez, S., and Lamberson, L. A. (2014). Ion Exchangeable Glasses. U.S. Patent 0308526 A1.

Chatelier, H. L. (1888). Recherches expérimentales et théoriques sur les équilibres chimiques. Ann Mines 13, 200.

Donald, I. W. (1989). Review methods for improving the mechanical properties of oxide glasses. J. Mater. Sci. 24, 4177-4208. doi:10.1007/BF00544488

Frischat, G. H., Adda, Y., Le Claire, A. D., Slifkin, L. M., and Wohlbier, F. H. (1975). Ionic Diffusion in Oxide Glasses. Diffusion and Defect Monograph Series. Zurich: Trans Tech Publications.

Garfinkel, H. M., and King, C. B. (1970). Ion concentration and stress in a chemically tempered glass. J. Am. Ceram. Soc. 53, 686-691. doi:10.1111/j.1151-2916.1970. tb12043.x

Iwamoto, N., Tsunawaki, Y., Hattori, T., and Mitsuishi, A. (1978). Raman spectra of $\mathrm{Na}_{2} \mathrm{O}-\mathrm{SiO}_{2}-\mathrm{Al}_{2} \mathrm{O}_{3}$ and $\mathrm{K}_{2} \mathrm{O}-\mathrm{SiO}_{2}-\mathrm{Al}_{2} \mathrm{O}_{3}$ glasses. Phys. Chem. Glasses $19,141-143$.

Jiang, L. B., Guo, X. T., Li, X. Y., Li, L., Zhang, G. L., and Yan, Y. (2013). Different K+$\mathrm{Na}^{+}$inter-diffusion kinetics between the air side and tin side of an ion-exchanged float aluminosilicate glass. Appl. Surf. Sci. 265, 889-894. doi:10.1016/ j.apsusc.2012.11.143

\section{AUTHOR CONTRIBUTIONS}

The manuscript was written through contributions of all authors. $\mathrm{HZ}$ and LW designed experiments; LW, FY, and BY carried out experiments; HZ, LW, JC, GC, and LS analyzed the experimental results. HZ and LW wrote the manuscript. All the authors have given approval to the final version of the manuscript.

\section{ACKNOWLEDGMENTS}

This work was supported by the National Natural Science Foundation of China (No. 21476083, No. 51572082); the Major Program of Science and Technology Commission of Shanghai Municipality (No. ZD14521100604); the Fundamental Research Funds for the Central Universities (No. WD1313009), and the Open Fund of the Key Laboratory for Ultrafine Materials of the Ministry of Education at East China University of Science and Technology. Furthermore, we would like to thank Dr. Guangjun Zhang and Dr. Feng He [Schott Glass Technology (Suzhou) Co., Ltd] for helpful discussions on glass structure.

Jin, Y. F., Jiang, D. H., Chen, X. S., Bian, B. Y., and Huang, X. H. (1986). Raman spectrum studies of the glasses in the system $\mathrm{Na}_{2} \mathrm{O}-\mathrm{Al}_{2} \mathrm{O}_{3}-\mathrm{P}_{2} \mathrm{O}_{5}$. J. Non Crystal. Solids 80, 147-151. doi:10.1016/0022-3093(86)90388-1

Karlsson, S., Jonson, B., and Stalhandske, C. (2010). The technology of chemical glass strengthening - a review. Glass Technol. Eur. J. Glass Sci. Technol. 51, 41-54.

Käfer, D., He, M. Q., Li, J. F., Pambianchi, M. S., Feng, J. W., Mauro, J. C., et al. (2013). Ultra-smooth and ultra-strong ion-exchanged glass as substrates for organic electronics. Adv. Funct. Mater. 23, 3233-3238. doi:10.1002/adfm. 201202009

Kistler, S. S. (1962). Stresses in glass produced by nonuniform exchange of monovalent ions. J. Am. Ceram. Soc. 45, 59-68. doi:10.1111/j.1151-2916.1962. tb11081.x

Lazzeri, M., and Mauri, F. (2003). First-principles calculation of vibrational Raman spectra in large systems: signature of small rings in crystalline $\mathrm{SiO}_{2}$. Phys. Rev. Lett. 90, 036401. doi:10.1103/PhysRevLett.90.036401

Matano, C. (1933). On the relation between the diffusion coefficients and concentrations of solid metals. Jpn. J Appl. Phys. 8, 109.

Mauro, J. C., Tandia, A., Vargheese, K. D., Mauro, Y. Z., and Smedskjaer, M. M. (2016). Accelerating the design of functional glasses through modeling. Chem. Mater. 28, 4267-4277. doi:10.1021/acs.chemmater.6b01054

Mysen, B. O. (1996). Phosphorus speciation changes across the glass transition in highly polymerized alkali silicate glasses and melts. J. Non Crystal. Solids 81, 1531-1534. doi:10.2138/am-1996-11-1227

Mysen, B. O. (1998). Phosphorus solubility mechanisms in haplogranitic aluminosilicate glass and melt: effect of temperature and aluminum content. Contrib. Mineral. Petrol. 133, 38-50. doi:10.1007/s004100050435

Nordberg, M. E., Mochel, E. L., Garfinkel, H. M., and Olcott, J.S. (1964). Strengthening by ion exchange. J. Am. Ceram. Soc. 47, 215-219. doi:10.111 1/j.1151-2916.1964.tb14399.x

Olcott, J. S. (1963). Chemical strengthening of glass. Science 140, 1189-1193. doi:10.1126/science.140.3572.1189

Potuzak, M., and Smedskjaer, M. M. (2014). Alkali diffusivity in alkaline earth sodium boroaluminosilicate glasses. Solid State Ionics. 263, 95-98. doi:10.1016/ j.ssi.2014.05.015

Sglavo, V. M. (2015). Chemical strengthening of soda lime silicate float glass: effect of small differences in the $\mathrm{KNO}_{3}$ bath. Int. J. Appl. Glass Sci. 6, 72-82. doi:10.1111/ijag.12101

Shen, J. W., Green, D. J., and Pantano, C. G. (2003). Control of concentration profiles in two step ion exchanged glass. Phys. Chem. Glasses 44, 284-292. 
Smedskjaer, M. M., Mauro, J. C., Sen, S., and Yue, Y. Z. (2010). Quantitative design of glassy materials using temperature-dependent constraint theory. Chem. Mater. 22, 5358-5365. doi:10.1021/cm1016799

Smedskjaer, M. M., Mauro, J. C., and Yue, Y. Z. (2015). Cation diffusivity and the mixed network former effect in borosilicate glasses. J. Phys. Chem. B 119, 7106-7115. doi:10.1021/acs.jpcb.5b03520

Solinov, V. F. (2015). Ways to strengthen glass: toughening, ion-exchange. Glass Ceram. 72, 191-193. doi:10.1007/s10717-015-9753-z

Stavrou, E., Palles, D., Kamitsos, E. I., Lipovskii, A., Tagantsev, D., Svirko, Y., et al. (2014). Vibrational study of thermally ion-exchanged sodium aluminoborosilicate glasses. J. Non Cryst. Solids 401, 232-236. doi:10.1016/ j.jnoncrysol.2013.12.017

Svenson, M. N., Thirion, L. M., Youngman, R. E., Mauro, J. C., Bauchy, M., Rzoska, S. J., et al. (2016). Effects of thermal and pressure histories on the chemical strengthening of sodium aluminosilicate glass. Front. Mater. 3:14. doi:10.3389/fmats.2016.00014

Svenson, M. N., Thirion, L. M., Youngman, R. E., Mauro, J. C., Rzoska, S. J., Bockowski, M., et al. (2014). Pressure-induced changes in interdiffusivity and compressive stress in chemically strengthened glass. ACS Appl. Mater. Interfaces 6, 10436-10444. doi:10.1021/am5019868

Toplis, M. J., and Schaller, T. (1998). A ${ }^{31} \mathrm{P}$ MAS NMR study of glasses in the system $x \mathrm{Na}_{2} \mathrm{O}-(1-x) \mathrm{Al}_{2} \mathrm{O}_{3}-2 \mathrm{SiO}_{2}-y \mathrm{P}_{2} \mathrm{O}_{5}$. J. Non Cryst. Solids 224, 57-68. doi:10.1016/ S0022-3093(97)00458-4

Vargheese, K. D., Tandia, A., and Mauro, J. C. (2014). Molecular dynamics simulations of ion-exchanged glass. J. Non Cryst. Solids 403, 107-112. doi:10.1016/ j.jnoncrysol.2014.07.025

Varshneya, A. K. (2010a). Chemical strengthening of glass: lessons learned and yet to be learned. Int. J. Appl. Glass Sci. 1, 131-142. doi:10.1111/j.2041-1294.2010. 00010.x
Varshneya, A. K. (2010b). The physics of chemical strengthening of glass: room for a new view. J. Non Cryst. Solids 356, 2289-2294. doi:10.1016/ j.jnoncrysol.2010.05.010

Wang, H. F., Han, W. J., and Wang, Y. M. (2008). The effect of ion exchange on glass surface morphology and composition. J. Non Cryst. Solids 354, 1146-1150. doi:10.1016/j.jnoncrysol.2006.11.054

Wiederhorn, S. M., Fett, T., Guin, J. P., and Ciccotti, M. (2013). Griffith cracks at the nanoscale. Int. J. Appl. Glass Sci. 4, 76-86. doi:10.1111/ijag.12025

Wondraczek, L., Mauro, J. C., Eckert, J., Kühn, U., Horbach, J., Deubener, J., et al. (2011). Towards ultrastrong glasses. Adv. Mater. 23, 4578-4586. doi:10.1002/ adma.201102795

Wu, Z., Shen, X. H., and Tian, Y. L. (2011). High Strength Aluminosilicate Glass and Chemically Toughening Process Thereof. CN101337770.

Zhang, G. J., Gerhard, L., José, Z., and Mathias, B. (2012). An Aluminosilicate Glass Containing $\mathrm{Li}_{2} \mathrm{O}$ and $\mathrm{P}_{2} \mathrm{O}_{5}$ Used for Chemical Toughening. W.O. Patent 2012/126394 A1.

Conflict of Interest Statement: The authors declare that the research was conducted in the absence of any commercial or financial relationships that could be construed as a potential conflict of interest.

Copyright (c) 2016 Zeng, Wang, Ye, Yang, Chen, Chen and Sun. This is an openaccess article distributed under the terms of the Creative Commons Attribution License (CC BY). The use, distribution or reproduction in other forums is permitted, provided the original author(s) or licensor are credited and that the original publication in this journal is cited, in accordance with accepted academic practice. No use, distribution or reproduction is permitted which does not comply with these terms. 